\title{
The Last Mile in Academic Publishing: Revising a Manuscript
}

Kara Chan

Hong Kong Baptist University

\begin{abstract}
Most of our journal or book manuscript submissions result in a request for revision according to the reviewers' comments. This article outlines the process of revising a manuscript, the options we have, and the tips of responding to reviewers' comments. It helps to reduce the frustration and inertia, and hopefully to make the publication journey less bumpy and more enjoyable.
\end{abstract}

Keywords: Academic publishing, revising

\section{Introduction}

This paper is based on an invited presentation at the Marketing in Asia Conference 2012 at Gyor, Hungary. Its objective is to help you achieve greater productivity in academic publishing by developing your competence in revising your manuscripts for book chapters or journal articles. The knowledge and skills involved include understanding the reviewing process and the reviewers' comments, dealing with the comments, and preparing your responses. I will also share with you a documentation system that you may find helpful in managing your research projects efficiently.

\section{Receiving the notification of submission results}

After months of waiting, the results come. You receive an email from a journal editor. It almost invariably says that while he or she enjoyed reading your manuscript, the reviewers have some suggestions. Based on their remarks, the editor asks you to revise your manuscript. There are two possible reactions to the news. "Wow, it is great! I have come closer to the goal. It is a great step toward its being accepted.” Or one can think, "Oh, this is so bad. I need to work on that blasted manuscript again. I'm sick of it. Why don't they just accept it as it is?”

Very often, the response will at that point be put aside for a while. People get upset and do not want to spend time on the revision. After a certain time, the author fails to follow through, and as a result the paper will forever remain on disk on the author's computer. 
Think of the time you have already invested in your study. You have probably spent three to six months or even more on the project, including writing the proposal for the funding, designing the study, collecting the data, and doing the analysis. You then put in another few weeks on the write-up and checking the references before you submitted the manuscript. The last mile of the run-the revision-will probably take you another five to ten days. If you fail to invest that time and energy, all your previous efforts go down the drain.

\section{What are my options?}

You need to pay close attention to what news the editor is actually communicating. It can be a conditional acceptance subject to your revision, or it can be an invitation for revision without commitment that the revised paper will be accepted. The former decision means that if you can revise it according the reviewers' comments, it will be accepted. The latter means that when you have revised it according the reviewers' comments, the editor will consider it again, but may still reject it. In either case you have three options. The first one, which is usually the most desirable, is to revise the manuscript according to the reviewers' comments and resubmit it to the same journal. If you can meet most of the reviewers' expectations, there's a good chance your manuscript will be accepted. The second option is to revise it according to the reviewers' major concerns, then submit it to another journal, but this is risky. Recall that the editor and the reviewers are contributing their time, unpaid, to help you improve your presentation. You can appropriate their comments to improve your chances of success at another journal, but the editor knows your name, and once you've exploited his help and taken it elsewhere he may feel no hesitation to share it with the reviewers and others in the field. Is your field of study really that large? Do you need to offend in this way? The third option is to do nothing and just send the manuscript off to another journal as it stands. This can be the best course if the editor has selected a reviewer who fundamentally disagrees with your entire approach or if the reviewers are asking for additional work which is far beyond your budget. A brief email of explanation should leave no hard feelings. But of course the editor of the new journal may by chance send the paper right back to one or both of the same reviewers. If you choose the second or third option, you'll still need to revise the citation and referencing style to meet the requirements of the new target journal.

Which option you choose depends on many factors, such as the quality of the original target journal, the estimated time it will take for the revisions they request, and how desperate you are for the paper to be accepted. If you have a major performance review such as tenure or a promotion review approaching, it is advisable to take the first option of re-submitting to the same journal. In that case you can at least show on your CV that the manuscript is in the second stage of review. It will sound more promising than just "submitted".

Nowadays the editor often gives you a deadline for the revision. It can vary from one to three months. This is a way to push the manuscript to either move forward or be rejected. Editors do not want a huge backlog of manuscripts in their pipeline. The reviewers may be reluctant to read the revised manuscript again if the original manuscript is submitted a long time ago. If you do not resubmit the revised 
manuscript by the specified time, the threat is that it will automatically be rejected. In fact, you can nearly always negotiate an extension if you have a good reason. So if you plan to revise and resubmit, send a reply email to the editor about your intentions, and if delays arise, keep him or her informed.

\section{How do I revise a manuscript?}

The three steps in revising a manuscript-preparing the revision, revising the text, and outlining the changes you have made in a response letter to the editor and reviewers.

First of all, you need to overcome your disappointment, anger, or even fear of not being accepted. The editorial decision is a fact that you cannot change, so live with it. Don't let negative feelings pull you down. Read the comments thoroughly to make sure you understand them. Sometimes you need to check with the editor if you do are not sure what a comment means. You don't need to agree totally with the reviewers, indeed you rarely will, but treat your reviewers as rare species including the few scholars in the world who can understand what you're writing and are willing to help you to improve it free of charge. They are your free publishing consultants.

You also need to see if outside help is needed and where you might get it. For example, the reviewer asks you to test the data using a structured equation model. If you have problem with it, you need to seek assistance from your network, perhaps a graduate student or a colleague. My practice is to make a hard copy of the manuscript and put it in a paper folder. If the reviewer suggests a paper or a book that you should make reference to, get the paper and put it in the same folder. Start reading those suggested papers as time permits.

If you have co-authors, it will be time to call for a meeting, perhaps using Skype if your co-author is from a different country. During the meeting, discuss what needs to be done and who is responsible for which part of the revision. Occasionally, you may need to go back to the original data and consider an alternative analytical approach. For example, a reviewer has pointed out that the age profiles of the two sub-samples in a cross-cultural study are not compatible. It may be necessary to remove a specific age in one sub-sample and re-do all the statistical analyses. If such measures are necessary, your original data set should be retrieved efficiently and correctly. That points to the importance of a good research documentation system, of which more later.

The second step is the revision itself. I call it the "operation”. Depending on your experience and skill, you may need to schedule three to five working days. You need blocks of uninterrupted working time. For me each block consists of about three hours. Sometimes you will need to rearrange your work and family schedule in order to construct these blocks. For example, I am a morning person. I try to start working by $8 \mathrm{am}$, and most likely I will not accept any incoming calls before 10am. Because of the accessibility of books and other reading materials, I usually do the revising in my office. 
Break down the "operation” into several smaller and more manageable tasks. Start with the easiest tasks first. The reviewers may, for example have asked you to further clarify the methodology or to add a citation, and such requests usually pose no difficulty. Do them and put a tick next to the reviewer's comment to indicate that you have tackled his or her concerns. Then work on the more tedious tasks such as amplifying the hypotheses or elaborating the discussion session. Work furiously, session by session, until you finish the operation. Make it a discipline that you don't overwork. If you overwork in one session you may be so exhausted that you have no energy to sustain the pace on the following day. You need to be persistent. Do little nice things for yourself to keep the momentum. If you have a collaborator, the process can be easier. You may find him or her willing to take care of some of the comments that you do not want to tackle. After the operation, go through the reference list again. You need to make sure that references have been added or removed appropriately.

After the revision has been completely drafted, read the manuscript over very carefully. See if the overall tone and manner is still fluent after all the changes here and there. If your university is supportive financially, this is the stage where you can bring in a technical editor. Some universities hire full time staff to provide proofreading services, but if you don't have regular staff at your university to read over your manuscript, consider hiring a professional proofreader on a project basis. I used to think that only non-native English speakers need proofreading service. I was wrong. A native English-speaking colleague told me he uses an editor for everything he writes and introduced his technical editor to me. Experienced technical editors can be difficult to find, but they read papers from mathematics to sewage treatment every day. In addition to correcting your grammatical mistakes, a good editor will be able evaluate your entire paper with a fresh perspective and sometimes spot details that you have overlooked. For example, I referred to the Dove's Evolution video in one of my papers. I treated it as a well-known case study, but my editor advised me to describe the campaign in detail, reminding me that not every reader would be familiar with it. Without that background, he himself found my arguments unclear. Proofreading fees of course vary significantly in different parts of the world. In Hong Kong, an editor charges you by the hour or by the number of words. I pay approximately US $\$ 400$ for a manuscript of about 5000 to 6000 words. You can consider approaching your departmental chair to request support for editing service.

Some journals require that you to highlight the parts of the manuscript where you have made significant changes. You can highlight the revised sentences or paragraphs with, for example, a different color. You are not expected to send in a word document with the changes tracked, as it is too hard to read. I prefer to use a bright blue color. According to a book titled "Thinking, Fast and Slow" by Nobel Prize winner in Economics Professor Daniel Kahneman, a clear and bright color is more likely to convince credibility.

The third step is almost a housekeeping job. Divide the reviewers' comments into sections that resemble a list of bullet points. Create a memo to be returned to the reviewer (via the editor) responding to the comments made point-by-point. For each point, insert a paragraph describing what you have done to respond, and explain why you did it. Here are two examples to illustrate how to tackle comments. The 
manuscript describes a qualitative study of young people's perceptions of public service advertisements.

Reviewer comment 1: “'We' is used in the paper. Was the study conducted by one interviewer, or by several interviewers? The limitations of the study should be clarified as there are perceived differences in interviewing techniques and styles.”

Response: We now clarify in the text that multiple interviewers were used for data collection. We also now state in the limitations section that there may have been interviewing bias because of different interviewing styles.

Reviewer comment 2: "The study is superficial and appears to investigate immediate responses. It could have investigated a much deeper level of thoughts, awareness, and emotions of the interviewees."

Response: In the original manuscript we classified the youths' responses to public service advertisements into likable and dislikable attributes. In the revised version we have reanalyzed the data and developed a framework with two dimensions. The first dimension classifies a response as positive or negative response; the second classifies it as emotional or evaluative. We hope you find this treatment more informative.

Thinking through how to deal with that second comment and revisiting the data took about one working day.

Of course you don't have to agree with all the suggestions proposed by the reviewers. Where you do not agree, say so and give your justification. For valid concerns that you are not able to deal with, recognize them in the manuscript as limitations. For example, if the reviewer suggests you need a bigger sample size, you probably cannot restart the data collection. You can only admit that the small sample is a limitation and recommend that a future study adopt a larger or more representative sample. Most editors will show understanding about these kinds of comments.

In preparing the reply memo I use another color (again, a bright blue color) to indicate the responses to improve the readability of the document. When all three steps have been completed, you need to re-submit before the deadline and wait for the good news.

In nineteen years as a full-time academic I have submitted approximately 120 manuscripts for journal papers and book chapters. About a quarter of those submissions were accepted without a request for revision. About an eighth were rejected or rejected after rounds (sometimes up to three rounds) of revision. But the rest, about sixty percent of them, were accepted after revision. So revising manuscripts is part of scholarly work. The better you can handle it, the more productive you will be. 
I have found that helping me revise is excellent training for junior colleagues. As a senior member in the department, I take the initiative to invite junior colleagues to coauthor with me. Very often they tell me that they learned a lot in handling reviewers' comments. They were able to see the manuscript from a new point of view and became aware of loopholes in the study. It seems to me that working together is a great way of mentoring junior colleagues and postgraduate students.

\section{Tracking your submission}

The turnaround time for the initial feedback from journals varies from six weeks to a few months. By the time you want to revise the manuscript, the first question will be "Which file is the version I submitted?" Take some time to organize your electronic files. Use one folder for each research project, and open a sub-folder solely for journal papers and conference presentations.

I use a table to monitor the progress of all my submissions. The table contains the title of the each manuscript, its filename on my computer, the journal or the book's publisher, the submission date, the date of initial reply from the editor, the resubmission date, the dates of any subsequent replies from the editor, and remarks. Each submitted manuscript can be seen as an egg, and you need to watch over them until they hatch.

Editors are dealing with volunteer reviewers, so they are reluctant to push them too hard. The reviewers have other responsibilities, and some may not find your paper very interesting. But if you hear nothing for three months after submitting a manuscript, you should contact the editor and ask about its status. Occasionally you may find the manuscript has been lost in the submission process. Sadly, most journals make no performance pledge about when an author will be notified of the initial decision. If you are eager to have some items on your $\mathrm{CV}$, you need to consider submitting to journals with quick turnaround time.

\section{Project documentation}

I like to have things organized; it makes me feel comfortable. There are a few files in the bookshelf that are the most important to my work. One contains all the questionnaires I have used in various studies. One contains all my published papers. For each study I have done I label a file "Documentation". It contains a one-page description of the project, as well as its survey document, if any. Figure 1 shows a sample one-page description of a project. Survey documents include the questionnaire with SPSS variable labels marked in red, or the coding frame for a content analysis study, or the interviewing guide for a qualitative study. The documentation file helps me acknowledge the source of funding in a journal paper, recall the method and data analysis used, and develop ideas for future studies. 


\section{Documentation for Project:}

Project Title: Tween girls' perception of gender roles and identities

Source of funding: CMCR research program

Data collection period \& method:

Sixteen girls aged 10 to 12 in HK were asked to keep a photo journal for a week. Specifically they took pictures from the media that could illustrate "What girls or women should or should not be, and what girls or women should or should not do". Qualitative interviews were conducted using the collected images as visual aids for illustration

\begin{tabular}{|l|l|}
\hline $\begin{array}{l}\text { Data in: } \\
\text { Tween girls sex identity } \\
\text { Interviews; pixs; content analysis of pixs }\end{array}$ & $\begin{array}{l}\text { Data analysis: } \\
\text { Excel files: 1. Should do or should be.xls } \\
\text { 2. paper 2 sexuality and media } \\
\text { scandal.xls } \\
\text { 3. paper 3 celebrities.xls } \\
\text { 4. paper 4 who create the images }\end{array}$ \\
\hline $\begin{array}{l}\text { Publications in } \\
\begin{array}{l}\text { 1. Young Consumers } \\
\text { 2. World summit yearbook }\end{array}\end{array}$ & $\begin{array}{l}\text { Presentations: } \\
\text { 3. Journalism and Mass Communication Faculty forum } \\
\text { 4. Journal of Children and Media }\end{array}$ \\
$\begin{array}{l}\text { World summit of children and } \\
\text { ICA Conference 2011 Boston }\end{array}$ \\
$\begin{array}{l}\text { Remark: Extension of the project for older girls: FRG (with Dr. R. Williams) } \\
\text { May consider develop a research monograph based on the results of both studies }\end{array}$ \\
\hline
\end{tabular}

Figure 1. A sample documentation page

You should always bring with you all your computer files, even if you are travelling abroad. Several times I have needed to work on a revision during an extended overseas trip. A file storage system in good order and well documented will enable you to perform on the road. But of course, don't forget to back up your hard disk 
regularly, at least once every month. The data files are your assets; keep them in good shape.

Nevertheless, good documentation is only a facilitator. It can help you to write better papers, but I have seen excellent publications by someone whom I know to be very disorganized. He succeeds anyway, despite the untidiness.

\section{Don't forget to celebrate}

When your revised manuscript is accepted, take time to celebrate. Go for a meal with your co-authors and research assistants. Or share the joy with someone you love or care about. Academic writing is a tough journey and needs a lot of positive thinking and social support. A celebration may help give you energy to continue with your next writing assignment. As a beginner in academic writing, a more experienced collaborator can be very beneficial. You feel that you are not a lonely traveler. You are accountable to one another in meeting deadlines and moving the project ahead. You can discuss ways to tackle specific reviewers' comments. How to find like-mind researchers? Attending academic conference is definitely one way. Hopefully, we shall meet each other at the next Marketing in Asia Group conference or on some other occasion.

\section{Suggested readings}

Boden, R., Epstein, D., and Kenway, J. (2005). Building your academic career, London, UK: Sage Publications.

Epstein, D., Kenway, J., and Boden, R. (2005). Writing for publication, London, UK: Sage Publications.

Hartley, J. (2008). Academic writing and publishing: a practical guide, Oxon, UK: Routledge. 